\title{
Improving neural network using a sine tree-seed algorithm for tuning motor DC
}

Widi Aribowo, Bambang Suprianto, Joko

Department of Electrical Engineering, Universitas Negeri Surabaya, Indonesia

\begin{tabular}{l}
\hline \hline Article Info \\
\hline Article history: \\
Received Oct 6, 2020 \\
Revised Feb 2, 2021 \\
Accepted Mar 23, 2021 \\
\hline
\end{tabular}

Keywords:

DC motor

Feed-forward neural network

Sine cosine algorithm

Sine tree-seed algorithm

Tree-seed algorithm

\begin{abstract}
A DC motor is applied to delicate speed and position in the industry. The stability and productivity of a system are keys for tuning of a DC motor speed. Stabilized speed is influenced by load sway and environmental factors. In this paper, a comparison study in diverse techniques to tune the speed of the DC motor with parameter uncertainties is showed. The research has discussed the application of the feed-forward neural network (FFNN) which is enhanced by a sine tree-seed algorithm (STSA). STSA is a hybrid method of the tree-seed algorithm (TSA) and Sine Cosine algorithm. The STSA method is aimed to improve TSA performance based on the sine cosine algorithm (SCA) method. A feed-forward neural network (FFNN) is popular and capable of nonlinear issues. The focus of the research is on the achievement speed of DC motor. In addition, the proposed method will be compared with proportional integral derivative (PID), FFNN, marine predator algorithm-feed-forward neural network (MPA-NN) and atom search algorithm-feed-forward neural network (ASO-NN). The performance of the speed from the proposed method has the best result. The settling time value of the proposed method is more stable than the PID method. The ITAE value of the STSA-NN method was $31.3 \%$ better than the PID method. Meanwhile, the ITSE value is $29.2 \%$ better than the PID method.
\end{abstract}

This is an open access article under the CC BY-SA license.

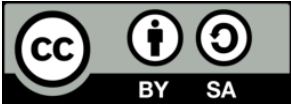

\section{Corresponding Author:}

Widi Aribowo

Departement of Electrical Engineering

Universitas Negeri Surabaya

Unesa Kampus Ketintang, Surabaya 61256, Jawa Timur, Indonesia

Email: widiaribowo@unesa.ac.id

\section{INTRODUCTION}

DC motor (direct current) is a basic electromechanical device that has the function to convert electrical power into mechanical power. DC motor is a type of motor that is used direct voltage as its power source. By providing a voltage difference at the two terminals, the motor will be rotating in one direction. If the polarity of the voltage is reversed, the direction rotation of the motor will be reversing as well. The polarity of the voltage is applied in the two terminals to determine the direction of rotation of the motor. DC motors have reliability, flexibility, and low cost. It is the reason why DC motor is very popular in industrial applications and household appliances that requires motor speed and position control. DC motors are most compatible with level speed control and are therefore applied in many adaptable speed drives [1].

DC motors have better speed characteristics than AC motors. In addition, the DC motors have an optimal speed control for breaking and acceleration. DC motors have a longer lifetime due to adjustments and variations in implementation. 
Conventional motor controllers such as PID controllers are still popularly applied [2]. This is due to the simple PID topology. The weakness of PID is to achieve high performance from a controller that has required accurate and precise control parameters. A good PID control setting will have an impact on optimal system response [3]. It is really depending on the parameter settings and the mathematical model. Classical methods have characteristics when modeling a non-linear system. This is influenced by the control equation which is complicated and required more effort.

This is stimulated the development of intelligent control technology [4]. The development of artificial intelligence is becoming an additional supplement in terms of control. In recent years, several researchers have started to apply several intelligent control methods based on artificial intelligence. Neural networks are the favorite method used because they have the ability to solve complex and non-linear problems. Several neural network methods are applied in applications such as forecasting [4], classification [5], estimation [6], and prediction [7]. Several studies on DC motor control are divided into two concepts, namely: conventional methods and artificial intelligence methods. several artificial intelligence concepts for controlling such as: Whale optimization algorithm [8], [9], Harris Hawks optimization algorithm [10], flower pollination algorithm [11], firefly algorithm [12], ant colony algorithm [13], [14], and neural network [15], [16].

Feed forward neural network (FFNN) has a simple and easy to implement network structure. FFNN is the favorite of the most widely implemented and is growing rapidly with a wide variety. Several computation methods have been widely applied to optimize neural networks such as the particle swarm optimization (PSO) method which is applied for weighting FFNN optimization [17], Genetic algorithm combined with FFNN [18], and a combination of gravitational search algorithm and FFNN [19].

Tree-seed algorithm (TSA) has the advantage that it can solve optimization problems. On the other hand, TSA has limited exploitation when dealing with complex problems. The sine-cosine algorithm (SCA) method has the advantage of balancing exploration and exploitation. The SCA can find promising areas of the search space and ultimately converge to the global optimal [20].

This research is proposing the sine tree-seed algorithm method to improve neural network skills. The limitations of the neural network in weighting will be handled by the sine tree-seed algorithm method. The method of the sine tree-seed algorithm is developed by combining the sine cosine algorithm and the tree seed algorithm [20]. The method of this research is called the STSA-NN hybrid method. The method is used to control the speed of a DC motor. The contribution of this research is to present intelligent control skills based on the Sine Tree-Seed Algorithm hybrid method and the neural network. The validation and effectiveness of the proposed method are compared with the PID, FFNN, MPA-NN and ASO-NN.

\section{MATERIALS AND METHODS}

\subsection{A sine tree-seed algorithm}

The method proposed by STSA-NN is a combination of STSA and NN methods. The STSA algorithm is an improvement in the Tree-Seed Algorithm (TSA) method using the Sine Cosine (SCA) method.

\subsubsection{TSA: Tree-seed algorithm}

TSA is a metaheuristic method that has a function as an intelligent optimization based on the relationship between trees and seeds. It is used to solve ongoing problems. At the start of the algorithm, the trees are planted above the ground. The location of the tree is placed with the best possible solution to the problem. The land is a representation of the search space. A control parameter called search tendency $(S T)$ is used to handle trees that have the best search tendency or taken randomly. The TSA method has the advantage of strengthening and blending locally to optimal or near-optimal.

Meanwhile, a very important optimization problem is to get a clear location generated from the tree. This is the focus of the search. New trees are created by replacing existing trees with new seeds that are deemed suitable and best. The tree and seed search method will be repeating until a specified number of function criteria are accommodated. In the early stages, initialize the tree is determined by.

$$
\begin{aligned}
& P_{i, j}^{t+1}=P_{j, \text { min }}^{t}+r_{i, j}^{t} \times\left(S H_{j, \text { max }}^{t}-S L_{j, \text { min }}^{t}\right) \\
& B_{i, j}^{t+1}=P_{i, j}^{t}+\alpha_{i, j}^{t} \times\left(B_{j, \text { max }}^{t}-P_{r, j}^{t}\right) \\
& B_{i, j}^{t+1}=P_{i, j}^{t+1}+\beta_{i, j}^{t} \times\left(P_{i, j}^{t}-P_{r, j}^{t}\right) \\
& B_{j, \text { max }}^{t}=\min \left(\int_{\left(P_{l, j}^{t+1}\right.}^{t+1}\right)
\end{aligned}
$$


Where dimension of the tree is $P_{i, j}^{t+1}$. The higher bound of the search space is $S H_{j, \text { max }}^{t}$. The lower bound of the search space is $S L_{j, \min }^{t}$. The random value with range [0,1] generated for each dimension is $r_{i, j}^{t}$. The dimension of the seed is $B_{i, j}^{t+1} . \alpha_{i, j}^{t} \cdot \beta_{i, j}^{t}$ are the scaling element which generated in series of [-1, 1] randomly. The dimension of top tree place is $B_{j, \max }^{t}$. The dimension of a tree randomly chosen from the population is $P_{r, j}^{t}$. For all test, the stop state is the peak times of function evaluations (MaxFE) and the amount of function evaluations $(F E)$.

$$
\begin{aligned}
& \operatorname{MaxFE}=M x 10000 \\
& F E=A
\end{aligned}
$$

Where $M$ is the dimension of a function, $A$ is the number of trees.

\subsubsection{SCA: Sine-cosine algorithm}

SCA is served to solve optimization problems with unknown search spaces using the sine and cosine functions. The location of each search agent is updated to get the optimal solution. SCA has an algorithm for combining high randomness of several solutions and random solutions which is useful for obtaining promising areas in the search space.

$$
\begin{aligned}
& V_{i}^{t+1}=V_{i}^{t}+r_{1}^{t} \times \sin \left(r_{2}^{t}\right) \times\left|r_{3}^{t} \times K_{1}^{t}-V_{i}^{t}\right|, r_{4}^{t}<0.5 \\
& V_{i}^{t+1}=V_{i}^{t}+r_{1}^{t} \times \cos \left(r_{2}^{t}\right) \times\left|r_{3}^{t} \times K_{1}^{t}-V_{i}^{t}\right|, r_{4}^{t} \geq 0.5
\end{aligned}
$$

Where the position of the current solution is $V_{i}^{t+1}$. The best solution obtained so far is $K_{1}^{t} \cdot r_{1}^{t}$ dictates the next place (or direction of movement), the distance from which the movement should move to the target or outward is $r_{2}^{t}$. A random weight for the goal so that stochastically emphasize $\left(r_{3}^{t}>1\right)$ or deemphasize $\left(r_{3}^{t}<1\right)$ the effect of desalination in defining the distance is $r_{3}^{t}$. A uniform switching between sine and cosine functions is $r_{4}^{t}$.

$$
r_{i}=a-t x \frac{a}{T}
$$

Where $t$ is the current iteration, $T$ is the maximum iterations, and $a$ is a constant.

\subsubsection{STSA: Sine tree-seed algorithm}

Seeds have an important role in the distribution and search for optimal value. This is not optimal due to random and simple seed production. Poor seed production will result in optimization results that are not in accordance with the optimal solution. The STSA method modifies the number of seeds ( $n s)$ value so that it can be processed according to changes in the $F E$ value. This has an effect on the amount that impacts on the best solution finding model.

$$
\begin{aligned}
& \text { ratioFE }=\frac{F E}{M a x F E} \\
& x \text { Theat }=0.5 \times \text { ratioFE } \times \pi \\
& n s=L \times \mid(H-L) \times \cos (x \text { Theat }) \mid+1 \\
& k=2 \times(1-\text { ratioFE })
\end{aligned}
$$

Where the number of seeds is $n s . L$ and $H$ are the low and upper bound of the number of seeds produced by a tree. A new parameter based on the original TSA which combines the inspiration of SCA is $k$. $k$ has range $[0,2]$. TSA has a weakness in the seed position updating function. Problems arise when the seed positions are separated. The position of this seed will have a large uncertainty value. This will be a factor causing the possibility of finding an optimal solution that is fast and accurate is getting smaller. On the other hand, SCA has good prowess in terms of global search capabilities. SCA has a balance in exploration and exploitation. 
The STSA algorithm integrates TSA with SCA to improve the ability to find optimal global stochastic solutions in optimization problems. The (2) and () in the TSA are replaced by.

$$
\begin{aligned}
& \mathrm{B}_{\mathrm{i}, \mathrm{j}}^{\mathrm{t}+1}=\text { tmprand } \times \mathrm{P}_{\mathrm{r}, \mathrm{j}}^{\mathrm{t}}+(1-\text { tmprand }) \times B_{j}^{t}, \text { rand }<0.5 S T \\
& B_{i, j}^{t+1}=P_{i, j}^{t}+k \times\left(B_{j}^{t}-P_{r, j}^{t} \times P_{i, j}^{t}\right) \times \sin \left(\pi \times \operatorname{acos}\left(P_{r, j}^{t}\right)\right), 0.5 S T \leq \text { rand }<0.5 S T \\
& \mathrm{~B}_{\mathrm{i}, \mathrm{j}}^{\mathrm{t}+1}=\mathrm{P}_{\mathrm{r}, \mathrm{j}}^{\mathrm{t}} \times \mathrm{P}_{\mathrm{i}, \mathrm{j}}^{\mathrm{t}}+\mathrm{k} \times\left(\mathrm{x}^{\mathrm{t}} \times \mathrm{P}_{\mathrm{i}, \mathrm{j}}^{\mathrm{t}}-\mathrm{P}_{\mathrm{r}, \mathrm{j}}^{\mathrm{t}}\right) \times \cos \left(\pi \mathrm{x} \arccos \left(\mathrm{x}^{\mathrm{t}}\right)\right), 0.5 S T \leq \text { rand }<0.5 S T
\end{aligned}
$$

Where $k$ is a new parameter based on the original TSA. The supervisor parameter for controlling the search trend is $S T$. Higher $S T$ supplies solid local search and accelerates convergence, and vice versa lower values lead to slow convergence but strong global search.

\subsection{Feed-forward neural network}

Neural networks are machine learning devices inspirited by biological neural networks and capable of processing with mimic as the human brain [21]. Artificial neural networks (ANN) could construct model linear and nonlinear algorithms. They are greatly answered as potent tools for the optimization function. The feed-forward neural network (FFNN) is to approximate and control nonlinear relationships between inputs and outputs. The data model needs to move in only one direction (forward) from the input nodes, via the hidden layers, and eventually to the output node. FFNN has a topology which consists of process units, which are represented by neurons. Figure 1 is the topology of FFNN. Neurons are the most important items of the FFNN which are governed by input, hidden layers and outputs. The input $\left(I_{n}\right)$ sends a signal to the hidden layer through a weighted network $\left(W_{i j}\right)$. In this section, the hidden neuron receives a weight plus bias input. Then, the neurons are directed to the output layer $\left(X_{4}\right)$. FFNN can be formulated as.

$$
\begin{aligned}
& X_{1}(t)=\sum_{i=1}^{j} W_{i j} I_{n}(\mathrm{t})+b_{1} \\
& X_{2}(t)=f\left(x_{1}(t)\right)=\frac{1}{1+\exp ^{x_{1}}} \\
& X_{3}(t)=\sum_{j=1}^{k} W_{j k} X_{2}(\mathrm{t})+b_{2} \\
& X_{4}(t)=f\left(X_{3}(t)\right)=\frac{1}{1+\exp ^{X_{3}}}
\end{aligned}
$$

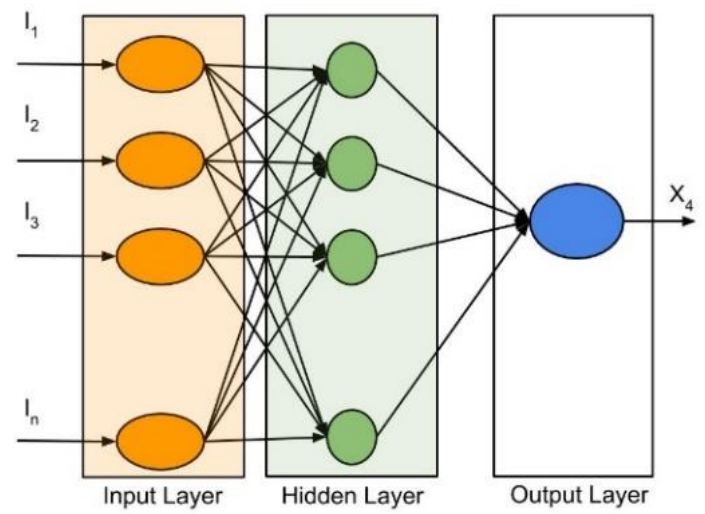

Figure 1. FFNN structure

\subsection{DC motor}

DC motor is a type of motor that uses speed and position control which is the armature control of the DC motor [22]. Armature control by keeping the static field current constant is key in DC motor setup [23]. The equivalent circuit is illustrated in Figure 2. 


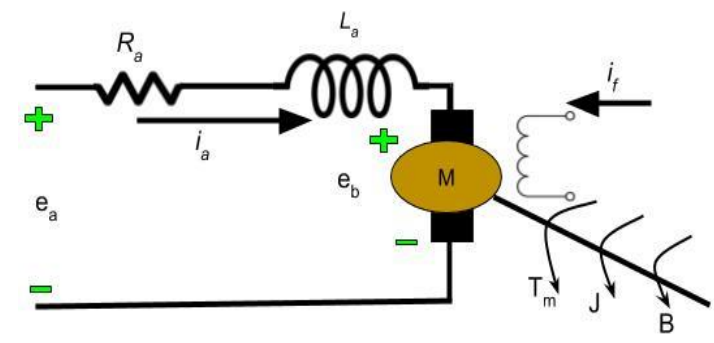

Table 1. DC motor parameters [25]

\begin{tabular}{cl}
\hline Notation & \multicolumn{1}{c}{ Information } \\
\hline$R_{a}$ & Armature resistance \\
$L_{a}$ & Armature inductance \\
$e_{a}$ & Armature voltage \\
$e_{b}$ & Back electromotive force \\
$J$ & Moment of intertia constant \\
$B$ & Damping friction ratio \\
$T_{m}$ & Motor torque \\
$K_{b}$ & EMF constant \\
$K_{i}$ & Moment constant \\
\hline
\end{tabular}

Figure 2. DC motor equivalent circuit [24]

$$
\begin{aligned}
& e_{a}(s)=\left(R_{a}+L_{a} \cdot s\right) \cdot I_{a}(s)+e_{b}(s) \\
& e_{b}(s)=K_{b} \omega(s) \\
& T_{m}(s)=J s \omega(s)+B \omega(s) \\
& T_{e}(s)=K_{i} I_{a}
\end{aligned}
$$

\subsection{The proposed STSA-NN model}

The flow chart of the STSA-NN hybrid method is presented in Figure 3 in Appendix. STSA and NN work independently. The two processes further have interacted with each other to form the STSA-NN method. In the method proposed by STSA-NN, data from the generator is taken as input and target for NN training. The data is processed and grouped. $\mathrm{NN}$ is set using several parameters. The weighting parameter at the beginning will be used a random value. This weight value will be increased using the STSA method. The weighted results from STSA will be stored in the NN.

\section{RESULTS AND DISCUSSION}

In the first step of the test, the DC motor is modeled on the MATLAB/Simulink (R2015a). DC motor modeling is regulated using the PID method. PID controller parameter values can be seen in Table 2. The necessary data were captured and grouped as a reference for the STSA-NN intelligent control training. Schematic of DC motor control using STSA-NN can be seen in Figure 4. The parameters and values used in the proposed STSA-NN method can be seen in Table 3. The convergence curve of STSA is reported in Figure 7.

In Figure 5, the convergence value of STSA stops at iteration 25. This result is obtained by entering the parameters contained in Table 3 in the STSA-NN algorithm. The next step, it is to install and test the STSA-NN controller on the DC Motor. The result of a closed loop system between the controller and the dc motor can be seen in Figure 6. Table 4 is a detail of DC Motor output wave.

Table 2. Parameter of PID controller

\begin{tabular}{cc}
\hline Parameter & Value \\
\hline $\mathrm{K}_{\mathrm{p}}$ & 2 \\
$\mathrm{~K}_{\mathrm{I}}$ & 6.5 \\
$\mathrm{~K}_{\mathrm{D}}$ & 0.01 \\
\hline
\end{tabular}

Table 3. Parameter of STSA-NN

\begin{tabular}{ll}
\hline Parameter & Value \\
\hline Hidden layer & 4 \\
Training & Levenberg-marquardt \\
Maximum iteration number & 50 \\
Number of populations & 50 \\
Lower bound; upper bound & $-1.28 ; 1.28$ \\
ST & 0.3 \\
Upper limit of seed's number & 0.1 \\
Lower limit of seed's number & 0.25 \\
\hline
\end{tabular}




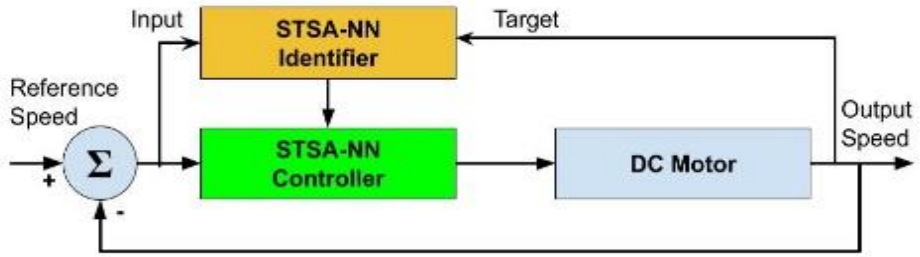

Figure 4. DC motor speed control with STSA-NN controller

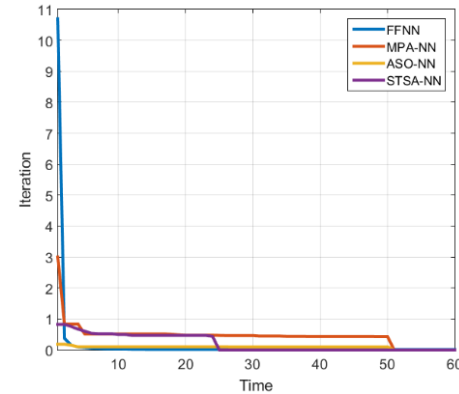

Figure 5. The convergence curve of STSA

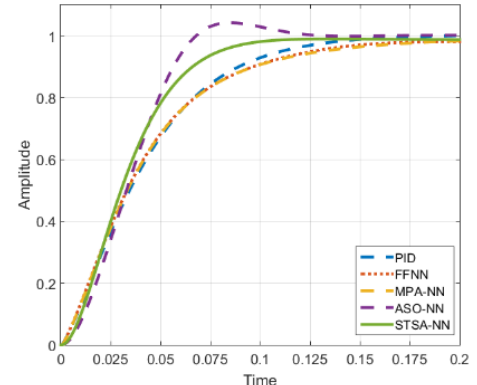

Figure 6. Speed step response of the DC motor

In Table 4, a comparative analysis of the proposed STSA-NN approach compared to PID is shown. To determine the effectiveness and validation of the proposed method, two criteria were used, namely Integral of time multiplied by squared error (ITSE) and Integral of time multiplied by absolute error (ITAE). ITSE has a supplementary time multiplier of the error function which points on the span of the error duration. This measurement is popular in the system takes quick tunning time. The ITSE index formula is given as.

$$
\operatorname{ITSE}=\int_{0}^{\infty} t \cdot e^{2}(t) \cdot d t
$$

ITAE is integrating the absolute error multiplied by time after time. Minimizing the integral of time-weighted absolute error (ITAE) is as usual pointed to as a good achievement index in plotting controllers.

$$
\operatorname{ITAE}=\int_{0}^{\infty} t \cdot e(t) \cdot d t
$$

The comparison of the ITAE and ITSE can be seen in Table 4. The ITAE value of the PID has value 0.5944. Meanwhile, the lowest ITAE value is owned by the ASO-NN method. It is 0.3357 . The lowest ITSE value is owned by the STSA-NN method of 0.1423. On the other hand, the highest value of ITSE is owned by the MPA-NN method of 0.2057

Table 4. Comparison of the transient response analysis results for different controllers.

\begin{tabular}{llcccc}
\hline Controller & \multicolumn{1}{c}{ Overshoot } & Settling Time (s) & Rise Time (s) & ITSE & ITAE \\
\hline PID & 1.0003 & 0.1375 & 0.081 & 0.2007 & 0.5944 \\
FFNN & No overshoot & 0.1375 & 0.08 & 0.2025 & 0.7155 \\
MPA-NN & No overshoot & 0.15 & 0.085 & 0.2057 & 0.7364 \\
ASO-NN & 1.042 & 0.13 & 0.04 & 0.1515 & 0.3357 \\
STSA-NN & No overshoot & 0.11 & 0.055 & 0.1423 & 0.4097 \\
\hline
\end{tabular}

\section{CONCLUSION}

Managing control on a DC motor is a very interesting research area. DC motor control that has a setpoint value must pay attention to the efficiency of the control. The sine tree-seed algorithm and neural network hybrid method proposed in this study is used to control DC motors. From the research results, the proposed method sine tree seed algorithm-neural network (STSA-NN) has a better performance on the settling time and ITAE parameters than the performance of PID. The ITAE value of the proposed method is 
0.4097. Meanwhile, the ITSE value of the proposed method has better performance than the PID value. It is 0.1423. The lowest ITAE value is owned by the ASO-NN method of 0.3357 . However, the ASO-NN method has an overshoot of 1.0423. To test the performance of the STSA-NN method, it is necessary to carry out further research with more complex problems.

\section{APPENDIX}

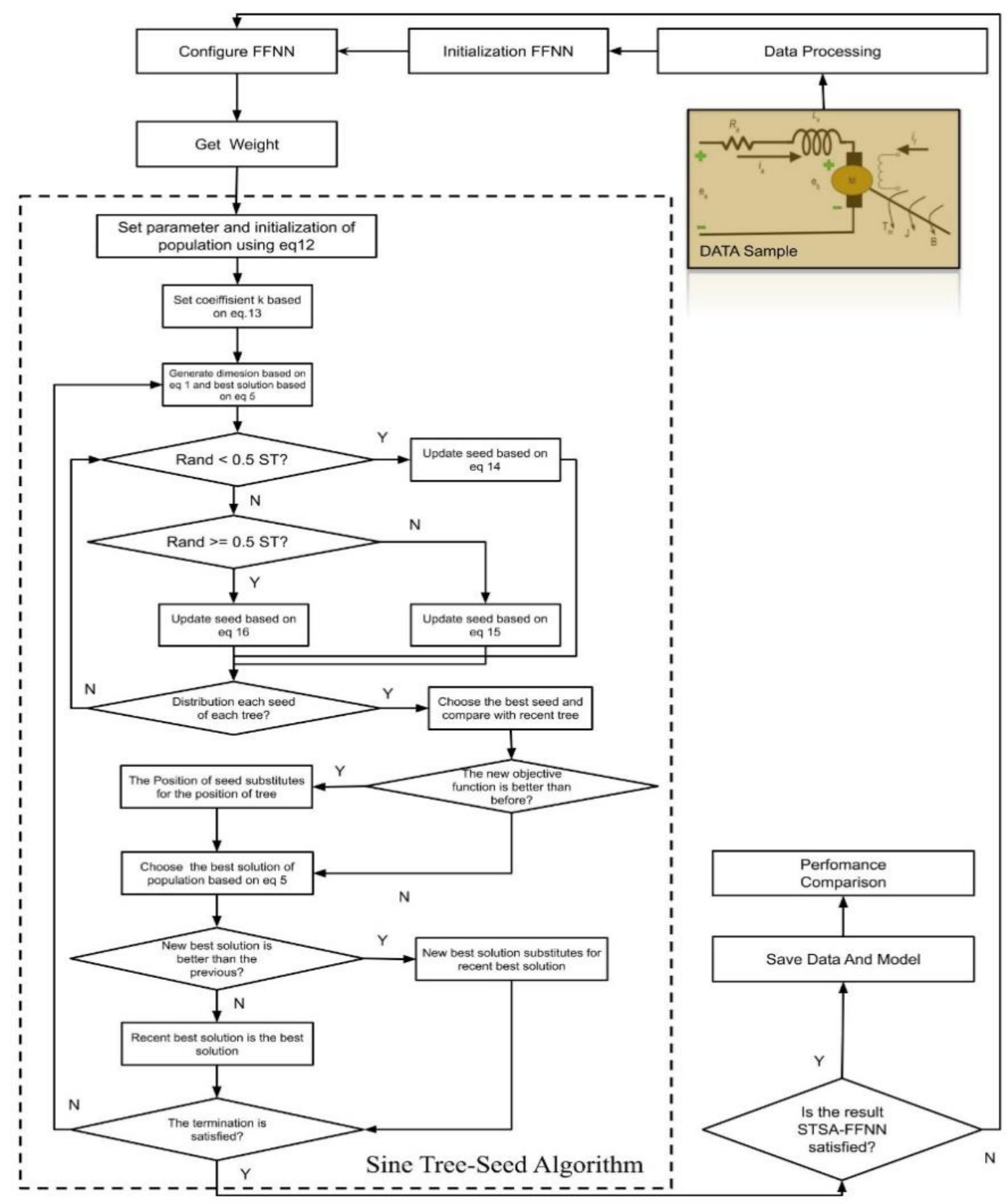

Figure 3. The proposed STSA-NN flowchart

\section{REFERENCES}

[1] A. Lotfy, M. Kaveh, M. R. Mosavi and A. R. Rahmati, "An enhanced fuzzy controller based on improved genetic algorithm for speed control of DC motors," Analog Integr Circ Sig Process, vol. 105, pp. 141-155, 2020, DOI: $10.1007 / \mathrm{s} 10470-020-01599-9$ 
[2] Bapayya Naidu Kommula, and Venkata Reddy Kota, "Direct instantaneous torque control of Brushless DC motor using firefly Algorithm based fractional order PID controller," Journal of King Saud University-Engineering Sciences, vol. 32, no. 2, pp. 133-140, 2020.

[3] Obed A. A., Saleh A. L., and Kadhim A. K., "Speed performance evaluation of BLDC motor based on dynamic wavelet neural network and PSO algorithm," International Journal of Power Electronics and Drive System (IJPEDS), vol. 10, no. 4, pp. 1742-1750, 2019, DOI: 10.11591/ijpeds.v10.i4.1742-1750.

[4] W. Aribowo, S. Muslim and I. Basuki, "Generalized regression neural network for long-term electricity load forecasting," 2020 International Conference on Smart Technology and Applications (ICoSTA), Surabaya, Indonesia, pp. 1-5, 2020, DOI: 10.1109/ICoSTA48221.2020.1570611361.

[5] Yasar, A., Saritas, I., Sahman, M.A., Dundar, A.O, "Classification of leaf type using artificial neural networks," Int. J. Intell. Syst. Appl. Eng. vol. 3, no. 4, pp. 136-139, 2015, DOI: 10.18201/ijisae.49279.

[6] Sulistyo. S.B, Woo. W.L, and Dlay. S.S, "Regularized neural networks fusion and genetic algorithm based on-field nitrogen status estimation of wheat plants," IEEE Trans. Industr. Inf. vol. 13, no. 1, pp. 103-114, 2016, DOI: 10.1109/TII.2016.2628439.

[7] Gu. K, Zhou. Y, Sun. H, Zhao. L, and Liu. S, "Prediction of air quality in Shenzhen based on neural network algorithm," Neural Comput. Appl., vol. 32, pp. 1879-1892, 2020, DOI: 10.1007/s00521-019-04492-3.

[8] B. Hekimoğlu, S. Ekinci, and S. Kaya, "Optimal PID controller design of DC-DC buck converter using whale optimization algorithm," in Proc. IEEE IDAP, Malatya, Turkey, Sep. 2018, pp. 1-6, DOI: 10.1109/IDAP.2018.8620833.

[9] B. Nayak and S. Sahu, "Parameter estimation of DC motor through whale optimization algorithm," International Journal of Power Electronics and Drive System (IJPEDS), vol. 10, no. 1, pp. 83-92, 2019, DOI: 10.11591/ijpeds.v10.i1.pp83-92.

[10] G. Nalcaci, D. Yildirim and M. Ermis, "Selective Harmonic Elimination for Light-Rail Transportation Motor Drives using Harris Hawks Algorithm," 2020 IEEE International Conference on Environment and Electrical Engineering and 2020 IEEE Industrial and Commercial Power Systems Europe (EEEIC / I\&CPS Europe), Madrid, Spain, 2020, pp. 1-6, DOI: 10.1109/EEEIC/ICPSEurope49358.2020.9160694.

[11] D. Puangdownreong, S. Hlungnamtip, C. Thammarat and A. Nawikavatan, "Application of flower pollination algorithm to parameter identification of DC motor model," 2017 International Electrical Engineering Congress (iEECON), Pattaya, 2017, pp. 1-4, DOI: 10.1109/IEECON.2017.8075889.

[12] B. N. Reddy Kota, "Direct instantaneous torque control of brushless DC motor using firefly algorithm based fractional order PID controller," Journal of King Saud University-Engineering Sciences, vol. 32, no. 2, pp. 133140, February 2020, DOI: 10.1016/j.jksues.2018.04.007.

[13] E. C. Şimşek, A. Köse, M. Şahin and E. Irmak, "Optimization of PID parameters using ant colony algorithm for position control of DC motor," 2019 8th International Conference on Renewable Energy Research and Applications (ICRERA), Brasov, Romania, 2019, pp. 1047-1051, DOI: 10.1109/ICRERA47325.2019.8997108.

[14] B. A. Kouassi, Y. Zhang, S. Ouattara and M. J. Mbyamm Kiki, " PID tuning of chopper fed speed control of DC motor based on ant colony optimization algorithm," 2019 IEEE 3rd International Electrical and Energy Conference (CIEEC), Beijing, China, 2019, pp. 407-412, DOI: 10.1109/CIEEC47146.2019.CIEEC-2019179.

[15] C. Fu, Q. -G. Wang, J. Yu and C. Lin, "Neural network-based finite-time command filtering control for switched nonlinear systems with backlash-like hysteresis," in IEEE Transactions on Neural Networks and Learning Systems, 2020, pp. 1-6, DOI: 10.1109/TNNLS.2020.3009871.

[16] C. Fu, L. Zhao, J. Yu, H. Yu, and C. Lin, "Neural network-based command filtered control for induction motors with input saturation," IET Control Theory and Applications, vol. 11, no. 15, pp. 2636-2642, 2017, DOI: 10.1049/iet-cta.2017.0059 IET

[17] S. Gajbhiye, M.A. Ghorbani, S.S. Band, V.K. Khosrowshahi and C. Meshram, "River flow prediction using hybrid PSOGSA algorithm based on feed-forward neural network," Soft Computing, vol. 23, no. 3, pp. 10429-10438, 2019, DOI: $10.1007 / \mathrm{s} 00500-018-3598-7$.

[18] X.J. Luo, Lukumon O.O., Anuoluwapo O.A., Olugbenga O.A., Delgado J.M.D, and Hakeem A.O., et al., "Genetic algorithm-determined deep feedforward neural network architecture for predicting electricity consumption in real buildings," Energy and AI, vol. 2, 2020, DOI: 10.1016/j.egyai.2020.100015.

[19] García-Ródenas, R., Linares, L.J. and López-Gómez. J.A, "Memetic algorithms for training feedforward neural networks: an approach based on gravitational search algorithm," Neural Comput \& Applic, vol. 33, no. 1, 2020, DOI: 10.1007/s00521-020-05131-y.

[20] Jianhua Jiang, Meirong Xu, Xianqiu Meng, Keqin Li, "STSA: A sine tree-seed algorithm for complex continuous optimization problems," Physica A: Statistical Mechanics and its Applications, vol. 537, 2020. DOI: 10.1016/j.physa.2019.122802.

[21] W. Aribowo, S. Muslim, munoto, B. Suprianto, U. T. Kartini and I. G. P. Asto Buditjahjanto, "Tuning of power system stabilizer using cascade forward backpropagation," 2020 Third International Conference on Vocational Education and Electrical Engineering (ICVEE), Surabaya, Indonesia, 2020, pp. 1-5, DOI: 10.1109/ICVEE50212.2020.9243204.

[22] Ramírez-Cárdenas, O.-D., and Trujillo-Romero, F, "Sensorless speed tracking of a brushless DC motor using a neural network," Math. Comput. Appl, vol. 25, no. 57, 2020, DOI: 10.3390/mca25030057.

[23] Badriyah Ahmed Obaid, Ameer Lateef Saleh, and Abbas Kareem Kadhim, "Resolving of optimal fractional PID controller for DC motor drive based on anti-windup by invasive weed optimization technique," Indonesian Journal of Electrical Engineering and Computer Science (IJEECS), vol. 15, no. 1, pp. 95-103, 2019, DOI: 10.11591/ijeecs.v15.i1.pp95-103. 
[24] S. J. Hammoodi, K.S. Flayyih, and A.R. Hamad, "Design and implementation speed control system of DC Motor based on PID control and Matlab Simulink," International Journal of Power Electronics and Drive System (IJPEDS), vol. 11, no. 1, pp. 127-134, March 2020, DOI: 10.11591/ijpeds.v11.i1.pp127-134.

[25] Amiri, M.S., Ibrahim, M.F., Ramli, R, "Optimal parameter estimation for a DC motor using genetic algorithm," International Journal of Power Electronics and Drive System (IJPEDS), vol. 11, no. 2, pp. 1047-1054, 2020, DOI: 10.11591/ijpeds.v11.i2.pp1047-1054.

\section{BIOGRAPHIES OF AUTHORS}

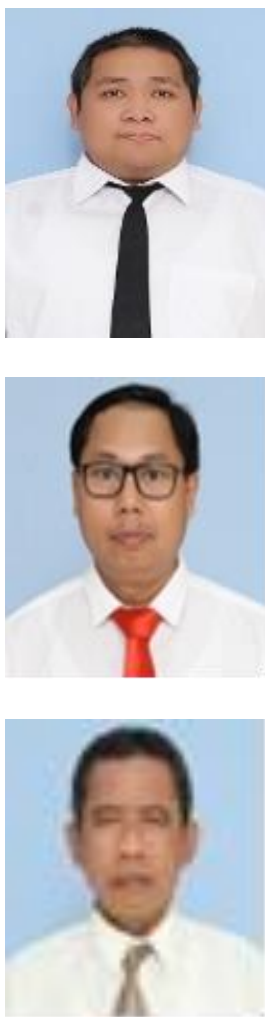

Widi Aribowo is a lecturer in the Department of Electrical Engineering, Universitas Negeri Surabaya, Indonesia. $\mathrm{He}$ is B.Sc in Power Engineering/Sepuluh Nopember Institute of Technology (ITS)-Surabaya in 2005. He is M.Eng in Power Engineering/Sepuluh Nopember Institute of Technology (ITS)-Surabaya in 2009. He is mainly research in the power system and control.

Bambang Suprianto is a lecturer in the Department of Electrical Engineering, Universitas Negeri Surabaya, Indonesia. He completed Bachelor of Electronic Engineering Education in Universitas Negeri Surabaya-Surabaya in 1986. He holds Master Engineering in Sepuluh Nopember Institute of Technology (ITS)-Surabaya in 2001. He was completed Doctor of Electrical Engineering in Sepuluh Nopember Institute of Technology (ITS)-Surabaya in 2012. His research interests include power system, control and electronic.

Joko is a lecturer in the Department of Electrical Engineering, Universitas Negeri Surabaya, Indonesia. He completed Bachelor of Electronic Engineering Education in Universitas Negeri Surabaya-Surabaya in 1989. He holds Master Engineering in Sepuluh Nopember Institute of Technology (ITS)-Surabaya in 2004. He was completed Doctor in Universitas Negeri MalangMalang in 2017. His research interests include power system and motor. 